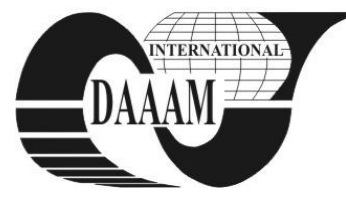

Annals of DAAAM for 2011 \& Proceedings of the 22nd International DAAAM Symposium, Volume 22, No. 1, ISSN 1726-9679 ISBN 978-3-901509-83-4, Editor B. Katalinic, Published by DAAAM International, Vienna, Austria, EU, 2011 Make Harmony between Technology and Nature, and Your Mind will Fly Free as a Bird Annals \& Proceedings of DAAAM International 2011

\title{
A MATURITY MODEL FOR QUALITY MANAGEMENT TO INCREASE THE ORGANIZATIONAL KNOWLEDGE
}

\author{
PASALODOS, D[avid] \& DOMINGO, R[osario]
}

\begin{abstract}
The paper presents a maturity model that links the principles of quality management with the organizational knowledge. To evaluate the maturity level of the quality management as tool to support the knowledge creation, three perspectives have been discussed: i) the application of the model generates knowledge in the organization, ii) the application of assessments to evaluate the model generates knowledge in the organization, and iii) the introduction of respective corrective actions to advance in the model generates knowledge in the organization.
\end{abstract}

Key words: organization, knowledge, model, quality, maturity

\section{INTRODUCTION}

Today is becoming increasingly important the relevance of people management in achieving the organizations` targets. Industrial strategies revitalize the central role that human management has on the competitiveness of productive environments. The need to consolidate a competitive advantage in organizations through its employees and collaborators has become a vital strategy in the global market that exists today which includes the management of knowledge resources effectively.

The connection between the fields of quality management and learning within the organization seems too obvious to experts. Thus, authors as Molina et al. (2007) and Barrow (1993) among others, recognize that the implementation of quality, with the consequent deployment of its basic principles and organizational learning are two aspects that are closely related. Among the various theories of maturity models is to be highlight two of them, the Capability Maturity Model Integrated (CMMI) developed by Software Engineering Institute (SEI) of Carnegie Mellon University, which is a reference model which differs from other models by the fact be based on practices to fit every production domain and have a holistic and integrated organization, with the aim of achieving the objectives (Kugler Maag Cie, 2006; Chrissis et al., 2006) and the second model the ISO / IEC TR 15504 that through the definition of a model and framework assess the development process according to levels defined by the standard (ISO, 1998).

Based on those studies it was created a maturity model to evaluate the excellence in the quality management of manufacturing organizations. The application of a model created with the principles of quality system, suppliers, customers and manufacturing development enhances the creation of knowledge in all areas of industrial environments. The combination as well of the existing maturity model theories guarantees a deeper know-how, a better result as well a continuous improvement.

The application of the model itself and respective assessments facilitate the transmission of knowledge and the generation of skills and abilities that allow a suitable and efficient performance of his task, improving the level of knowledge in parallel with the level achieved base on the model. In addition encourages all persons in a productive environment to speak the same language (possess a common knowledge and use the same methods) that is support by the use of a framework provided by the standard reference model.

\section{MATURITY MODEL AND KNOWLEDGE TRANSMISION}

Although a high degree of automation in any industrial systems, they are operated by people so the key is to give them the necessary tools they can perform his tasks as much effectively and efficiently as possible, creating value added knowledge. Evenfalls, it is difficult to assess the knowledge creation in a production environment since there is not a mathematical formulation to measure it.

In order to achieve and sustain a competitive advantage in the global economy, organizations today need to manage their knowledge resources efficiently (Liebowitz et al. 2007) which means they have to learn faster than the competitors. The model created increases the internal knowledge in the organization by implementing a global/standardized process aligned with the organization's strategy and based on a common set of competences, taking advantage of possible synergies of locations with similar development needs and finding clever and effective ways to close the gaps. The application of model to evaluate excellence (or maturity level) in quality management is presented under the premise that the quality of a product or service is highly influenced by the quality of the processes that produce and maintain it as well as cooperation with suppliers (Yang et al., 2009) and knowledge of the requirements and needs of customers (Pyon et al., 2010).

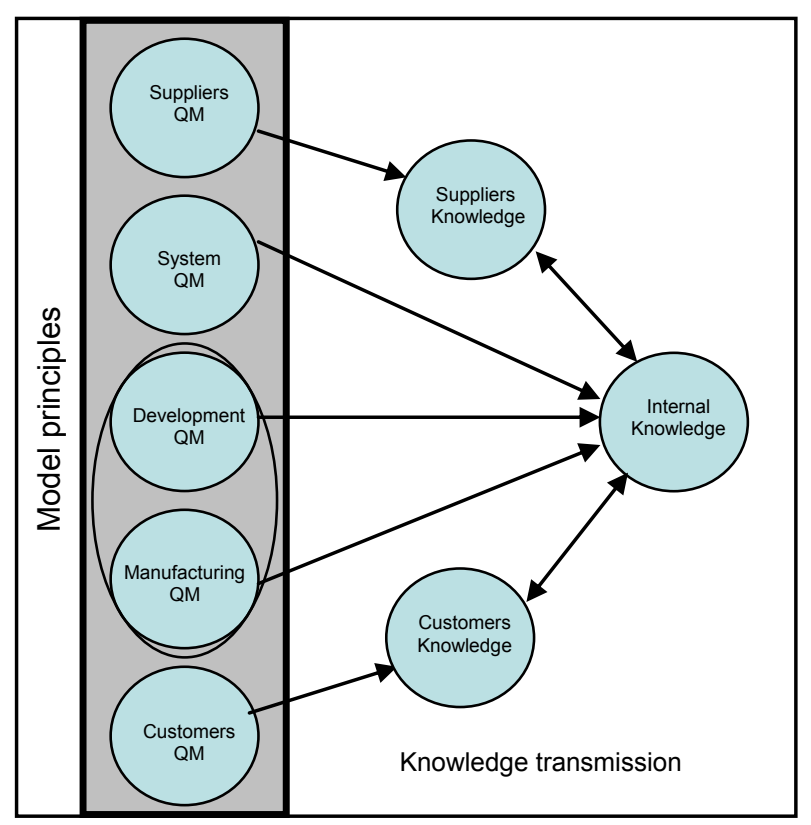

Fig. 1. Knowledge transmission through the model 
The developed model is divided in 4 sub-principles (system, supplier, manufacturing \& development and customers) and each of them is also divided in single methods and practices.

As presented in the Figure 1 the application of the model principles help to extend the partnership beyond the borders of the productive environment and increase the cooperation, promoting the creation of a network of external contacts and knowledge.

Even principle has a positive impact on flexibility and responsiveness of the organization in the design and production process, so it is very important to understand the common target and identify the differences between the respective manufacturing sites, especially when talking about a multinational organization because it comes into play the role of different languages and cultures.

\section{RESULT AND DISCUSSION FROM MODEL APPLICATION}

The model allows to build confidence, helping to polish and discover employee's skills to put new ideas into action and developing them in a continuous improvement context, increasing efficiency that comes from knowing how to act in an appropriate way. The model creates knowledge in the 11 manufacturing sites evaluated from three different points of view:

a) The application of the model generates knowledge in the organization

The application of the model is a project focused on people of the organization (employees, suppliers, customers) clearly, beginning with the continuous focus on customer satisfaction in the most efficient way possible.

It is a global system approach (not an isolated area or program), and an integral part of corporate strategy, it works both horizontally and vertically across all functions and departments, involving all employees, giving a clear strategy to introduce and develop methods and tools as well as the respective improvement actions introduced after the respective evaluations to approach the management system to the reference model.

Based on this, the application of a model and its respective evaluations emphasizes learning and continuous improvement as the key to competitive success, investing in its development as well as in people to improve their level of knowledge both internally and externally (customers and suppliers).

The incorporation and development of methods and tools implicates also learn how to use them. In this sense, it is important to highlight also the possible role of common knowledge owned by the members of the organization increasing the sharing, integration and assimilation of knowledge that takes place in groups or teams during the learning and knowledge creation.

b) The application of assessments to evaluate the model generates knowledge in the organization

The assessment approach to evaluate the level of the organizations respect the applied model brings visibility and generates insights into how the organization performs, improving information exchange by enabling a feedback loop. One of the key factors of successful organizations is the measurement and assessment of the resources they have and require.

It enables the organizations to capture feedback and information from broad cross-section of the model as well as knowledge sharing. When this information is examined and analyzed it generates organizational knowledge that can be used for future decision-making.

Building an assessment system to evaluate continuously the level of maturity means that people involved have a wide understanding of the organization and increase its knowledge.
The organization learns and creates new knowledge developing and increasing the existing one.

c) The introduction of respective corrective actions to advance in the model generates knowledge in the organization

The implementation of the necessary actions to increase the maturity level respect the model involves changes in the actual way to work and employees need to adapt themselves, through learning, enhancing the development of knowledge capable of sustain a competitive advantage, increasing transparency.

By the implementation of the respective improvement actions is enhanced teamwork, considered key to achieving excellence in management, accounting for close collaboration between managers, employees, customers and suppliers.

\section{CONCLUSIONS}

A reference model to evaluate the maturity level of the quality management represents a good tool and a consistent system to develop skills on employees, but in an effective way. Besides, this tool should support the strategic decisions inside the organizations with the creation of organizational know-how.

The paper has considered these questions, which have been treated in an industrial environmental. The thinking is that the model allows increasing the existing knowledge as well as creating new one and developing it in a continuous way from the application.

Moreover the assessments to evaluate the status respect the model and the implementation of the necessary methods and practices to increase the level of maturity of the quality management respect to the model, are the following steps to carry out in the future.

\section{REFERENCES}

Barrow, J.W. (1993). Does Total Quality Management Equal Organizational Learning?. Quality Progress, July, 39-43, ISSN 0033-524X

Chrissis, M.B.; Konrad, M. \& Shrum, S. (2006). CMMI Second Edition: Guidelines for Process Integration and Product Improvement. Addison-Wesley, ISBN 978-0321154965

ISO/IEC TR 15504-5:1998. Information technology - Software process assessment Part 5: An assessment model and indicator guidance. International Organization for Standards, Geneve

Kugler Maag Cie GmbH (2006). CMMI for Development Version 1.2. Carnegie Mellon University

Liebowitz, J.; Ayyavoo, N.; Nguyen, H.; Carran, D. \& Simien, J. (2007). Cross generational knowledge flows in edge organizations. Industrial Management and Data Systems, Vol.107, No. 8, pp.1123-1153, ISSN 0263-5577

Molina, L.M.; Lloréns-Montes, J. \& Ruiz-Moreno, A. (2007). Relationship between quality management practices and knowledge transfer. Journal of Operations Management, Vol. 25, No. 3, pp. 682-701, ISSN 0272-6963

Pyon, C.U.; Woo, J.Y. \& Park, S.C. (2010). Intelligent service quality management system based on analysis and forecast of VOC. Expert Systems with Applications, Vol. 37, No. 2, pp. 1056-1064, ISSN 0957-4174

Yang, J.; Wong, C.; Kee-hung, L. \& Ngome, A. (2009). The antecedents of dyadic quality performance and its effect on buyer-supplier relationship improvement. International Journal of Production Economics, Vol.120, pp. 243-251, ISSN 0925-5273 